\title{
COMPRENDER LA BURBUJA INMOBILIARIA EN ESPAÑA \\ Una visión mediatizada desde la publicidad
}

\section{Antonio Raúl Fernández Rincón}

Universidad de Murcia (UM), Espinardo, Murcia, Espanha. E-mail: antonioraul.fernandez@um.es

\section{Eneus Trindade}

Universidade de São Paulo (USP), São Paulo - SP, Brasil. E-mail: eneustrindade@usp.br

\section{Pedro Antonio Hellín Ortuño}

Universidad de Murcia (UM), Espinardo, Murcia, Espanha. E-mail: phellin@um.es

DOI: $10.17666 / 329512 / 2017$

\section{Introducción}

El objetivo de este artículo es esbozar las bases teóricas para la construcción de un modelo de estudio del discurso de la publicidad inmobiliaria. Pretendemos ofrecer una alternativa en términos teóricos que reúna las principales aportaciones en este ámbito y sirva para ampliar la comprensión del fenómeno a partir de una mirada interdisciplinar. Construimos nuestra proposición teórica a partir de cuatro grandes bloques:

1 Estudios sobre el mercado de la vivienda desde el ámbito de la economía, la sociología y la antropología.

2 Aportaciones teóricas recientes en el ámbito de la comunicación, la publicidad, la mediatización y el consumo.
3 Reflexiones en torno a la vivienda y la arquitectura en la sociedad contemporánea.

4 Destacados estudios precedentes sobre semiótica y retórica del discurso en la publicidad inmobiliaria.

De todos ellos extraemos aquellos aspectos que estimamos pueden contribuir a generar una visión teórica más ajustada del discurso de la publicidad inmobiliaria. Es decir la vivienda como sector estratégico de alta relevancia cuyas trascendencias exceden el ámbito económico, para incluir aspectos psicológicos, sociológicos, antropológicos, culturales y sociales. El papel que la publicidad como industria de la cultura, desempeña en la sociedad contemporánea. El consumo que, en línea con las aportaciones de Miller (2012) es entendido hoy como un proceso fundamental en la vida de las familias y en la construcción de disposiciones más amplias como la expresión de 
los valores fundamentales o las creencias acerca del mundo. El concepto de mediatización como eje central de las discusiones actuales en torno a los estudios sobre comunicación y que constituirá el pegamento esencial que conecte las diferentes áreas que componen nuestra proposición.

Nuestro objeto de estudio es la publicidad inmobiliaria, con vistas a reflexionar sobre el discurso de anunciantes y marcas más allá del análisis textual de los mensajes. Para ello se hace necesario dotar a este propósito de una fundamentación teórica que abarque diferentes áreas relacionadas con las ciencias sociales. El marco teórico, siguiendo los preceptos de Castro y Calvo (1995), está dirigido a establecer un modelo o modelos explicativos que puedan ser utilizados para analizar e intervenir en el objeto de la investigación. Como explica Schwarz (2013), en el marco teórico reside el conocimiento mínimo que se requiere para comprender el problema a investigar, en nuestro caso la publicidad inmobiliaria. Para ello, realizamos una revisión hermenéutica de los avances investigativos, paradigmas, metodologías o formas de abordar de forma directa o tangencial el objeto de estudio para poder transitar caminos metodológicos y conceptuales inéditos.

En una fase posterior, el diseño de un modelo metodológico y una investigación empírica puede arrojar importantes conclusiones acerca de las características y peculiaridades de la publicidad inmobiliaria en España. Este mismo análisis podría aplicarse en el contexto actual y el pasado reciente al terreno abonado para generar datos relevantes en las recientes burbujas inmobiliarias vividas en países como Estados Unidos, Japón, Inglaterra, Irlanda, España, Grecia o Portugal, cuyos datos podrían utilizarse para generar nuevos análisis en otras zonas donde existen indicios de formación de nuevas burbujas, como en el caso de China, Australia, Nueva Zelanda o Brasil. El caso de Brasil es relevante en nuestro caso, no sólo porque un buen número de los estudios encontrados sobre publicidad inmobiliaria proceden de aquí, sino porque como exponen Manarin (2010) o Mendonça y Sachsida (2012), el país podría estar gestando el inicio de una burbuja inmobiliaria similar a la vivida en España durante la década de 1990.

\section{El mercado de la vivienda}

La vivienda trasciende la esfera de lo económico y lo financiero, constituyéndose como un bien de consumo relacionado con aspectos sociales, políticos y culturales. El desarrollo exponencial del mercado inmobiliario durante la pasada década, ha sido un fenómeno global que ha afectado a un buen número de países industrializados. En países como España, Grecia, Irlanda, Estados Unidos o Japón, se habla de auténticas "burbujas inmobiliarias”. En línea con Stiglitz (1990) y Schiller (2003), la burbuja inmobiliaria, como cualquier otro tipo de burbuja, existe cuando la única razón que mantiene un aumento de los precios - de la vivienda en nuestro caso - es la creencia de los inversores de un rendimiento mayor en el futuro y no el análisis de factores fundamentales. Esta situación de entusiasmo irracional de los inversores, se extiende por contagio psicológico de persona a persona creando una burbuja.

A propósito de la denominada por Burriel de Orueta (2008): "década prodigiosa del urbanismo español” entre 1997 y 2006, recurrimos a las obras de: Juan (2000); Montalvo (2003); Campos Echevarría, (2008); Gramlich, (2008); Trias de Bes, (2009) y las cifras del Instituto Nacional de Estadística (INE). Durante este período se iniciaron un total de 5.626.312 viviendas en España, lo que supuso un ratio anual de 13,3 viviendas por cada 1.000 habitantes, una cifra que duplica la tasa de formación de hogares en Europa para el mismo período.

Como señalábamos en Hellín y Fernández (2015), el descubrimiento del sector inmobiliario como motor de desarrollo económico en la década de los noventa, encontró como carburante esencial un contexto político y financiero más que favorable a través de sucesivos Planes de Vivienda estatales, una legislación que, entre otras cosas, favorecía el abaratamiento del suelo y ante todo una serie de medidas transnacionales destinadas a favorecer el consumo y la inversión a partir de bajadas continuas de los tipos de interés; el dinero barato. En algunos años de este período entre 2002 y 2006 los tipos de interés reales fueron incluso negativos. La fiesta del crédito hizo que en 2002 un $92 \%$ de los créditos concedidos tuvieran como finalidad la ad- 
Tabla 1

Viviendas Iniciadas en España

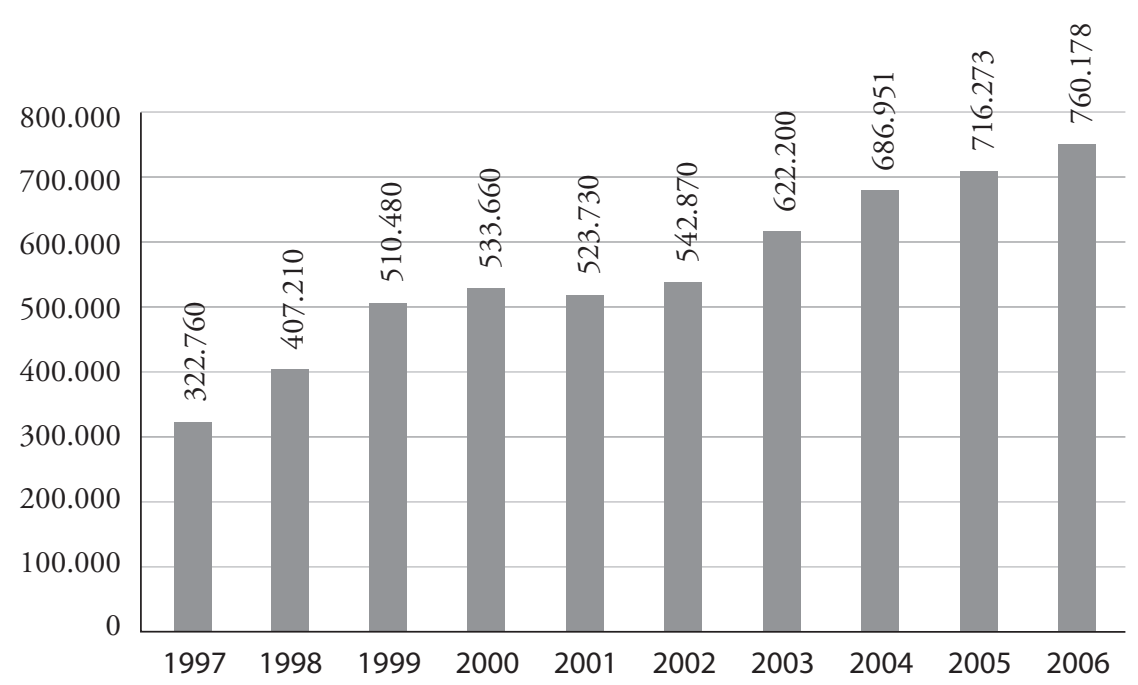

Fuente: INE y elaboración propia.

quisición de vivienda. En este contexto se desata una euforia irracional, basada en la creencia generalizada de un rendimiento futuro asegurado de los valores inmobiliarios. Los hogares españoles se lanzan a una aventura inversionista que en 1996 les lleva a destinar a la adquisición de vivienda el 50\% de su renta bruta disponible y en 2002 cerca del 80\%.

Otro dato relevante de este período es la revalorización de la vivienda. España durante esta etapa se situó a la cabeza de las economías desarrolladas.

El sector financiero también desempeñó un rol decisivo en este contexto. En los países donde hubo más incidencia de la burbuja inmobiliaria se aprecia un interés desmedido por bancos, cajas de ahorro y cooperativas de crédito por el sector de la vivienda. Una cartera centrada en el sector de la vivienda y el suelo, aseguraba rendimientos futuros y favorecía en muchos casos la expansión geográfica de las entidades. En 2012 España solicitó una línea de crédito o ayuda financiera a la Unión Europea de hasta 100.000 millones de euros para rescatar a las entidades bancarias que no pudieron sostener la fiesta del crédito barato al inicio de la crisis financiera internacional de 2008. La condición que la Comisión Europea estableció para la concesión de este rescate, incluía entre otros aspectos, la necesidad de acome- ter una severa reestructuración con vistas a contraer el volumen de sucursales, reducir sus balances en torno al $60 \%$ y centrar sus modelos de crecimiento empresarial en los préstamos al por menor y las pymes. La génesis de estos sucesos solo puede comprenderse a escala global como afirma Abadía (2009). Cuando en 2001 tras la explosión de la burbuja de Internet, la Reserva Federal estadounidense bajó en dos años el precio del dinero del $6,5 \%$ al $1 \%$, el contagio de

Tabla 2

Revalorización de la Vivienda (1997-2006). Según datos de The Economist

\begin{tabular}{lc}
\hline Alemanha & $-1 \%$ \\
\hline Australia & $126 \%$ \\
\hline Espańa & $173 \%$ \\
\hline Estados Unidos & $98 \%$ \\
\hline Francia & $120 \%$ \\
\hline Hong Kong & $-31 \%$ \\
\hline Italia & $88 \%$ \\
\hline Reino Unido & $184 \%$ \\
\hline Japón & $-28 \%$ \\
\hline
\end{tabular}

Fuente: Trias de Bes (2009) y elaboración propia. 
los tipos de interés baratos dopó el mercado de la vivienda. $\mathrm{Al}$ obtener menos rendimiento por cada operación, las entidades necesitan aumentar el volumen de estos, concediendo préstamos más arriesgados o hipotecas subprime. A principios de 2007 los precios de la vivienda se desplomaron pero en el mercado ya estaba copado de hipotecas muy por encima del valor de las viviendas. Comienzan a producirse impagos a lo que sigue una crisis de liquidez, una crisis bursátil en enero de 2008 y una crisis económica a escala internacional.

El colapso de la burbuja inmobiliaria en España provocó una cadena de efectos negativos en el empleo, en las industrias adyacentes y en el sector financiero. La sobresaturación del mercado de la vivienda no sólo ha dejado un amplio y fantasmal paisaje de viviendas vacías y proyectos inacabados, también arrastra una elevada deuda pública y privada que se ha instalado en los cimientos de la sociedad y que supone un lastre para la recuperación económica que otros países del entorno parecen superar. Una realidad que para Serrano, García y Lagar (2016) tiene sus raíces años atrás y que por lo tanto, no debe ser interpretada como un ciclo económico aislado, sino a partir de la confluencia de factores sociológicos, económicos, políticos y culturales. De esta forma, asistimos durante este periodo a fenómenos como la ingente afluencia de inmigrantes, atraídos por la supuesta bonanza económica, la expansión de las ciudades con áreas residenciales (casas unifamiliares), la consideración generalizada de la vivienda como activo de inversión o la multiplicación de segundas viviendas en zonas de playa y montańa, para dar respuesta a la demanda proveniente del turismo residencial y vacacional.

Coincidimos con Bourdieu (2003) cuando afirma que tratar la vivienda como un mero bien económico supone un reduccionismo inaceptable. Significa abstraerlo del sistema de estrategias de reproducción de las que es un instrumento, ignorar sus propiedades históricas, su relevante inserción en el tejido social y su función afectiva al encerrar un proyecto de reproducción biológica y social. En el ámbito de lo material, resulta apropiado hablar de la vivienda como bien de consumo pero no un bien de consumo más. Al igual que la vestimenta, la vivienda se expone a la percepción pública, expresando como casi ningún otro bien el ser social de su propietario. Se trata de un producto dotado de un componente simbólico muy fuerte que además lleva asociado un importante componente patrimonial para las familias. La vivienda junto a la alimentación, el vestuario, las herramientas, las monedas, los pueblos y las ciudades y los hombres, integran lo que Braudel (1970) vino a denominar "vida material", forma parte de la historia de lo cotidiano (De Certeau, 1994), con sus estrategias y tácticas, con importantes vínculos con el mundo material y simbólico (Douglas \& Isherwood, 1978). La casa, allí donde se encuentre, expresa aquello que las culturas se obstinan en conservar y en repetir. Además, la vivienda como bien de consumo es también un camino para la expresión de la identidad individual self como afirma Campbell (2001).

El estudio teórico y empírico de Bourdieu (2003) propone una mirada sociológica y antropológica sobre el mercado de la vivienda en Francia, que en el fondo sirve para desvincular a la economía de cualquier concepción mecanicista. Introduce el autor también aquí sus conceptos de habitus y "campo" al referirse a la demanda y oferta de viviendas respectivamente. En el consumo de viviendas se incorporan en diferentes proporciones de capital económico, simbólico y cultural, dando lugar a disposiciones incorporadas o habitus. En la oferta de viviendas se dan cita igualmente diferentes posiciones competitivas de las empresas o posiciones de mercado (campo). Tras el estudio, el autor se reafirma en la creencia de que la "estructura del capital" económico, cultural o simbólico, influye decisivamente en el consumo de las viviendas. En el orden de lo simbólico, el discurso publicitario juega un papel esencial. El autor analiza anuncios de viviendas para descubrir cómo la publicidad moviliza un discurso capaz de hacer resurgir experiencias únicas, comunes, singulares y triviales asociadas a la casa. El efecto simbólico de este, es el resultado de una colaboración entre el autor y lector. El primero es capaz de despertar de forma encantadora experiencias únicas expresando el patrimonio cultural en palabras e imágenes. El segundo proyecta sobre el texto correspondencias, analogías y resonancias que le permiten reconocerse en él, haciéndolo suyo, dejándose poseer. 


\section{Sistema publicitario, mediatización y consumo}

La apropiación del patrimonio cultural que realiza el discurso publicitario es ya un lugar común en el que confluyen la gran mayoría de autores, ya sean del ámbito estrictamente publicitario o desde otras ciencias sociales. En este sentido, las aportaciones de autores como Williamson (1978); González Martín (1982); Aaker y Myers (1984); Augé (1989); Ibáñez (1994); Hernández (1998); Rusell y Lane (2001); Eguizábal (2007); Hellín Ortuño (2007); San Nicolás Romera (2008); Codeluppi (2007); Benavides (2012), coinciden en afirmar que la publicidad es una actividad económica, cultural y social. Viene jugando un papel esencial al albor del capitalismo moderno y las economías más avanzadas. Un contexto sin el que hubiera resultado imposible su desarrollo, por ser un sistema vinculado al beneficio, el consumo y el concepto de estado-nación. Se trata de una actividad ligada al mito de la libertad, la tecnología, la formación de núcleos urbanos y la generación de una conciencia colectiva. Su poder estetizante como factoría de símbolos es el carburante que moviliza buena parte de los actos sociales, las creencias, las actitudes y comportamientos. El sistema publicitario desempeña un rol decisivo en la configuración de identidades, hábitos de consumo, deseos, aspiraciones e imaginarios colectivos.

Si consideramos la vivienda no como un bien de consumo más, el propio acto del consumo tampoco debería considerarse un acto de consumo más. Para ello introducimos el concepto de "consumo mediatizado". Aunque las aportaciones en el terreno del consumo no son aún todo lo extensas que cabría desear, sí existe un considerable corpus teórico en el ámbito de la mediatización.

El concepto de mediatización ha encontrado tradicionalmente relevancia en ámbitos como la religión, la política o el deporte (Mazzoleni y Schulz, 1999; Hjarvard, 2008; Strömbäck, 2008). La presencia de los medios en estos ámbitos, unida a las discusiones sociológicas en torno a la interacción social de los medios, hace de la mediatización un fenómeno que a pesar de mostrarse como contemporáneo hunde sus raíces más allá de la actual con- figuración del ecosistema mediático. Constituye hoy una de las discusiones centrales en comunicación, a partir de la cual se desarrollan muy diversas aplicaciones y estudios en humanidades y ciencias sociales, con el fin de entender procesos de cambio social, cultural y material. Mediatización y cambio climático, política, diplomacia, propaganda, relaciones personales, migraciones, cultura popular, ciencia, moral e incluso la muerte (Lundby, 2014).

El origen podría situarse como una forma de entender la centralidad y relevancia creciente de los medios en los procesos sociales (Couldry y Hepp, 2013). Para los autores, el término surge a consecuencia del crecimiento en el rol que desempeńan los medios a partir del año 2000 y en los países industrializados. El incremento de la velocidad de acceso a internet, la universalización de dispositivos móviles y la emergente cultura del conocimiento compartido a través de plataformas como blogs, wikis o redes sociales, constituyen un punto de referencia central en la vida de las personas. La omnipresencia multidireccional de los medios requiere por tanto, un estudio que vaya más allá del tradicional triángulo cerrado "producción-texto-audiencia”, hacia una configuración no lineal y abierta.

Hepp (2014) en torno a la investigación sobre el concepto de mediatización distingue dos corrientes o tradiciones: la tradición institucionalista y la social-constructivista. La tradición institucionalista surge a partir de los estudios sobre el mensaje periodístico y la comunicación política. En términos generales, esta corriente concibe a los medios como instituciones sociales independientes con sus propias lógicas de actuación. Siguiendo a Hjarvard (2008), mediatización se refiere a la adaptación de diferentes ámbitos de la sociedad como la política o la religión a esas formas de actuación. Reglas que Altheide y Snow (1979) definen como "lógicas mediáticas". Desde una perspectiva institucionalista, mediatización además debe ser entendida como un proceso asociado a la posmodernidad, ya que los medios no sólo están sujetos a las transformaciones de la sociedad moderna, sino que actúan como agentes de modernización al operar como instituciones que desempeñan un papel esencial en la configuración de una realidad colectiva (Hjarvard, 2014). Esta concepción de la mediatización como 
un proceso asociado a una modernidad tardía que se aceleró en los últimos años del siglo XX, es cuestionada por Eliseo Verón (2014) desde una perspectiva antropológica. Así, la mediatización para el autor es el resultado operacional de una dimensión nuclear de la especie humana, su capacidad semiótica. Esta capacidad ha sido activada por diferentes razones en diversos contextos históricos y se expresa en lo que denomina "fenómenos mediáticos" que no son otra cosa que la exteriorización de procesos mentales en forma de dispositivos materiales. La primera etapa de la semiosis humana se remonta al uso de herramientas de piedra como sistemas sígnicos

La tradición social-constructivista entiende por mediatización el esencial rol que los medios desempeñan en el proceso de la construcción de la realidad social y cultural. El origen de esta corriente se encuentra en el interaccionismo simbólico, la sociología del conocimiento y la teoría de los medios. Más allá de las lógicas mediáticas, esta visión se muestra más amplia ya que, como afirman Couldry y Hepp (2013), se refiere a la construcción comunicativa de la realidad social y cultural, en línea con las aportaciones de Berger y Luckmann (1967), expresada por el conjunto de los medios. El interés reside, entonces, en comprender cómo ese proceso se manifiesta en los procesos mediáticos y cuáles son las consecuencias para la vida de las personas.

A pesar de las distancias que puedan percibirse entre ambas corrientes, las diferencias son tan sutiles que el propio autor reconoce la coexistencia e interrelación entre ambas al afirmar que por un lado, la tradición institucionalista está reconsiderando el concepto de "lógica mediática" y por otra parte la tradición social-constructivista está poniendo el énfasis en la necesidad de investigar la dimensión institucional de la mediatización. A partir de las discusiones sobre la existencia y coexistencia de ambas tradiciones, en sentido amplio, la mediatización es un concepto usado para analizar de forma crítica la interrelación entre los cambios en los medios y la comunicación por una parte y los cambios en la cultura y la sociedad por otra (Couldry y Hepp, 2013, p. 197). El concepto hace referencia a aspectos tanto cuantitativos como cualitativos. Cuantitativos porque se refiere a la creciente expansión espacio temporal de la comunicación mediada. En algunos contextos la comunicación mediada es más amplia que otras formas de comunicación en términos cuantitativos. En lo que respecta a los aspectos cualitativos, se refiere a la especificidad de ciertos medios dentro de cambio sociocultural, qué tipo de medio es utilizado para qué tipo de comunicación. A partir de las ideas de Orozco (1997); Silverstone (2002), Martín Barbero (2003); Couldry y Hepp (2013) y Hjarvard (2012) podemos establecer las principales diferencias entre mediatización y mediación.

Bajo esta perspectiva teórico-metodológica, la comunicación se encuentra en la centralidad de la formación política y cultural de las sociedades o dicho de otro modo, los procesos culturales están vinculados a los medios.

\begin{tabular}{ll}
\hline Mediación & Mediatización \\
\hline $\begin{array}{l}\text { Referida al proceso de comunicación en general y su } \\
\text { participación en la construcción de significados. }\end{array}$ & $\begin{array}{l}\text { Referida al papel de los medios de comunicación en } \\
\text { los procesos emergentes de cambio sociocultural. }\end{array}$ \\
\hline Es un concepto más amplio. & Es un concepto más restringido \\
\hline $\begin{array}{l}\text { Estudia la comunicación a través de un medio en un } \\
\text { contexto social específico cuya intervención puede afectar } \\
\text { tanto al mensaje como a la relación entre el emisor y el } \\
\text { receptor. }\end{array}$ & $\begin{array}{l}\text { Contempla un proceso más a largo plazo, según el } \\
\text { cual las instituciones sociales y culturales y sus modos } \\
\text { influencia creciente de los medios }\end{array}$ \\
\hline
\end{tabular}

Mediación se refiere a un momento clave relacionado con Mediatización describe cambios. el concepto de interacción simbólica a partir de nuevas formas de transmisión (medios)

Fuente: Elaboración propia. 
Las conexiones entre mediatización y consumo pueden encontrarse en las propuestas de Hjarvard (2012), Trindade y Perez (2014) y García Canclini (1995). Existe una mediatización directa y otra indirecta. La directa es cuando una determinada actividad pasa a ser ejecutada de una forma diferente debido a la influencia de los medios. Por ejemplo, buscar una vivienda en Internet o incluso visitarlas a través de realidad virtual. La forma indirecta de mediatización hace referencia a la influencia cada vez mayor de los medios en una determinada actividad, sin afectar significativamente a la forma en que se realiza. Por ejemplo, la forma en la que elegimos nuestras viviendas o cómo las decoramos, está cada vez más está permeada por la imagen retransmitida por los medios. La diferencia entre ambas estaría por tanto en una especie de gradiente de influencia donde la forma indirecta se muestra más débil, más sutil. Las formas de mediatización directa e indirecta en muchas ocasiones operan en combinación, resultando difícil distinguirlas. En los procesos de consumo, precisamente sería un ámbito en el que ambas formas pueden concurrir. Mientras que el consumo online sería un claro ejemplo de mediatización directa, la presencia de los medios en los procesos de compra, proponiendo determinados rituales de consumo en sus diferentes contenidos, sugiere un ejemplo de mediatización indirecta.

Para comprender la presencia de los medios en los actos de consumo, la mirada antropológica que verifica las interacciones entre marcas y consumidores de McCracken (2003) y las aportaciones foucaultianas de Agamben (2010) abren una perspectiva semio-discursiva, antropológica y cultural que explica cómo se produce la transferencia de sentido, valores y significados desde los bienes de consumo a los consumidores. El consumo aparece demarcado por procesos de transferencia de significado desde un mundo socialmente construido hacia los bienes de consumo y de estos hacia el consumidor a través de dos vectores esenciales: el sistema publicitario y la moda. Ambos ejercen su papel sugiriendo prácticas ritualistas de poseer los bienes, de adquirirlos, cambiarlos o despojarnos de ellos. Estos rituales de consumo actúan a su vez como dispositivos mediáticos ya que, como apunta, pueden ser cualquier cosa capaz de capturar, orientar, determinar, in- terceptar, modelar, controlar y asegurar los gestos, conductas, opiniones y discursos de las personas.

Schulz (2004) en torno a la relación entre mediatización y consumo se coloca a medio camino entre la tradición institucionalista y social-constructivista. Si la comunicación humana ha estado constreñida por limitaciones espacio temporales, los medios diluyen estas limitaciones convirtiéndose en lo que Mcluhan (1967) definía como "extensiones del hombre". Los medios además están sustituyendo actividades e instituciones sociales o cambiando su carácter y formas tradicionales de comunicación. De este modo, la mediatización influye en el consumo a través de procesos de extensión, sustitución, amalgama y acomodación. La consecuencia más radical de la influencia de la mediatización en el consumo es el proceso de sustitución, según el cual determinadas actividades sociales vienen siendo sustituidas por actividades mediadas. El caso más extendido es el de las compras online. Por ejemplo, escuchamos la radio mientras conducimos o miramos la televisión mientras comemos. Los medios actúan además como catalizadores de cambios sociales, desde el momento en que su relevancia social supone el sustento de personas e instituciones, contribuyendo en buena medida al crecimiento de la riqueza y el sostenimiento de industrias culturales. De este modo, agentes económicos diversos acomodan su forma de actuar a la operativa de los medios. Esto es claramente visible en deportistas, políticos y profesionales del entretenimiento y la cultura. En definitiva, los medios ofrecen nuevas formas de consumir productos y servicios, más allá de limitaciones geográficas u horarias (Eskjær, 2013). Habermas (1971) y después Ritzer (2010) usaron la expresión "implosión del consumo" para describir cómo mediante el cual este ha dejado que residir en la esfera de la intimidad para vivir en la esfera social.

\section{Vivienda, arquitectura y mediatización}

La mediatización del consumo inmobiliario se suma al discurso arquitectónico que a su vez es otro modo de mediatización. En la arquitectura también encontramos marcas en sus diversas formas de expresión. Estas marcas se refieren a los productos en venta, a las marcas personales de los arquitectos y a las empresas constructoras y promotoras. Estas 
comparten los valores contemporáneos de la Posmodernidad (Hellín Ortuño, 2007) que son difundidos como significados de los espacios y sentidos de las viviendas para los consumidores. Esos sentidos de la vida material inmobiliaria se involucran en lógicas y prácticas que se manifiestan en los rituales de consumo de estos productos.

La arquitectura es considerada hoy un lenguaje estético privilegiado de la cultura posmoderna. Para poner de manifiesto su dimensión simbólica como disciplina entregada a la imagen y la mercadotecnia, recurrimos a las obras de Jenks (1996), Ibelings (1998), Sklair (2010) o Moix (2010), Augé (2008), Colomina (2010), Amendola (2000), Baudrillard (2007) e Ibáñez (1994).

Los conceptos de iconicismo e historicismo y el influjo de la semiótica en la década de los setenta, hicieron que la arquitectura empezara a concebirse como un vehículo de significación. Lo icónico en arquitectónica se refiere a su significación simbólica aplicada a los edificios, espacios y en algunos casos a los propios arquitectos. El concepto "neo": el pastiche, el simulacro que marca y define una sociedad entregada al valor de cambio. Un concepto que si en arquitectura define la moda de mezclar y canibalizar estilos arquitectónicos pasados, para Baudrillard (2007) se materializa culturalmente en una primacía de la representación. Todo ello deriva en lo que Ibáñez (1994) definiría como la semantización de los objetos de consumo. A continuación, como vimos más arriba en McCracken (2003), la transferencia semántica del mundo culturalmente construido para los bienes y de los bienes para los consumidores se realiza por medio de los rituales de representación de los sistemas publicitario y de la moda. Amendola (2000) también habla de indeterminación, ambigüedad, fragmentación, patchwork y bricolaje proyectual, como constantes de la experiencia urbana posmoderna. Para el autor, más que en los edificios en sí, el habitar posmoderno se desarrolla en la ciudad. Ámbito en el que se impone en efecto a las conciencias individuales experiencias y pruebas muy nuevas de soledad, directamente ligadas a la aparición y a la proliferación de los "no lugares" (Augé, 2008). Los "no lugares" ejemplifican las formas que caracterizan la condición de la sobremodernidad: un exceso o abundancia de espacio, de signos y de individualiza- ción radical. La visión convencional de la arquitectura como una disciplina artística elevada, ha dado paso en el siglo XX a un fenómeno embebido en la cultura de masas. El edificio moderno se entiende tal y como se hace la fotografía, la ilustración, el cine o la publicidad. Para Colomina (2010) los medios de comunicación se han constituido como lugares de producción arquitectónica, la arquitectura es entendida como una serie de sistemas de representación.

La arquitectura icónica contemporánea, al igual que el mercado de la vivienda, apunta conexiones teóricas sustantivas entre con la "cultura-ideología del consumismo" en el marco de una teoría crítica de la globalización. En la era de la globalización, la arquitectura icónica busca convertir todo el espacio público en un espacio que, de una u otra forma, está destinado al consumo. De este modo, la arquitectura se concibe como un proyecto hegemónico de la clase capitalista transnacional. Un ejemplo latente de esto lo encontramos en las "catedrales del consumo" de Ritzer (2000) que son espacios que trascienden las diferencias geográficas, étnicas y culturales.

\section{Estudios sobre publicidad inmobiliaria}

Habida cuenta de las trascendencias del mercado inmobiliario y teniendo presente la sobresaturación de oferta que ha tenido lugar en buena parte de los países industrializados en las últimas décadas, podríamos entender que, de igual forma, el sector ha movilizado una gran cantidad de recursos comunicativos que activaran la demanda. El de la vivienda es un sector transversal, cuyo devenir afecta a otros sectores como el empleo, las materias primas, la energía o la comunicación. A pesar de ello una revisión en torno a las principales bases de datos de ciencias sociales a escala internacional, (Web of science, Scopus, ProQuest Lista, Isoc, Eric, IneBase, Jstor Dialnet, y otros) ofrece un panorama ciertamente escaso de estudios relacionados con la comunicación en el sector inmobiliario. El mayor volumen de obras sobre la vivienda se refiere a estudios económicos y financieros, sobre todo a raíz de las burbujas inmobiliarias de la década de los noventa y la posterior recesión internacional. 
Las aportaciones sobre publicidad inmobiliaria como disciplina asociada al derecho hipotecario también son comunes y no deben confundirse con nuestro objeto de estudio. Aquella acepción se refiere al conjunto de técnicas destinadas a la publicidad de los actos jurídicos sobre la propiedad. El marketing inmobiliario igualmente ha adquirido cierta relevancia en los últimos ańos. Se trata de obras destinadas a exponer las principales técnicas y procesos relacionados con la venta de productos inmobiliarios para los diferentes agentes que intervienen en el sector. En último lugar encontramos estudios centrados en el análisis del discurso de la publicidad inmobiliaria. Es el caso de autores como Williams, Qualls y Grier (1995); Renno (2003); Ferraz y Possidônio (2004); Días Alves (2008); Collins y Kearns (2008); Pryce y Oates (2008); Mejía Escalante (2009); Al-Homoud y Al-Oun et. al. (2009); Helio Junquera (2010); Livier \& Hernández (2010); Henrique, (2011); Barrera, (2011); Paranhos Ferreira (2012); Songqing (2012); Mazaj (2012); Lawson, (2013); Gómez y Racciati (2013).

La vivienda a pesar de ser un bien de consumo más, en muchas ocasiones, el producto aún no existe más que en las recreaciones hiperrealistas que realiza el constructor o promotor, una forma de consumo anticipado del signo. Este hecho despierta el interés de los estudios centrados en la retórica clásica y la mitología, procedentes en su mayoría ámbito iberoamericano. Esta orientación desvela cómo la publicidad inmobiliaria crea lugares simbólicos de residencia y pertenencia como extensión de la identidad. Inmersos en los procesos de construcción y reafirmación de la ideología del bienestar en la ciudad a partir de los medios de comunicación, la publicidad inmobiliaria es la encargada de materializar lugares simbólicos que persiguen efectos ilusorios sobre la conciencia del individuo. Este mismo individuo no sentirá que todos sus problemas vitales se solucionan pero al menos obtendrá una forma de consuelo que le ayudará y reconfortará. El lenguaje de este discurso varía en función de la situación estructural y económica del mercado en cada momento y el contexto territorial en el que se da.

La semiótica de la cultura y los preceptos de Semprini (2006) y Greimas (1984), evidencian el giro semiótico contemporáneo hacia el que la publicidad inmobiliaria ha transitado en las últimas décadas. Asistimos a un cierto refinamiento donde la vivienda, como un producto más y dotada de una marca, hace uso de valores referidos a grupos sociales para construir su propio sistema en el que confluyen las ideas del vendedor y los deseos del futuro morador. La publicidad inmobiliaria es capaz de generar imaginarios sociales a través de los cuales los compradores obtienen satisfacciones vitales, prestigio y/o valor. Este hecho es visto desde ciertas posiciones como una intrusión ideológica de poderes públicos y privados que de algún modo distorsiona la percepción de la habitabilidad de determinados entornos urbanos. A veces estos imaginarios tienen que ver con axiomas posmodernos como el retorno a la naturaleza, lo idílico, lo edénico, los jardines, las zonas verdes y la relación antitética entre el campo y la ciudad. La comercialización de viviendas puede ser usada como un sitio potencial de transformación ética de los valores relacionados con los nuevos desarrollos urbanos.

En ocasiones, el discurso de la publicidad inmobiliaria se articula a partir de la construcción de dos tipos de imaginarios, uno de corte más funcional, propio de anunciantes con un perfil más cercano a la ingeniería y otro más connotativo, simbólico y seductor, que viene a estar identificado con anunciantes dedicados a la promoción y venta de inmuebles. Este último está asociado a una madurez acelerada del discurso publicitario en las últimas décadas, pues presenta un cierto refinamiento. Motivado previsiblemente por la necesidad de dar salida a una gran oferta de viviendas construidas, la publicidad inmobiliaria pasa de ser un subsector casi marginal de la actividad, restringida a espacios acotados en el medio prensa, a generar importantes volúmenes de trabajo para el sector publicitario. Pasa a convertirse en un anunciante más, que difunde sus mensajes a través de medios de publicidad al uso como la televisión, la radio, la prensa o el exterior, Internet y los canales de promoción directa.

Desde el ámbito sociológico, la publicidad inmobiliaria sirve también como herramienta para estudiar la incidencia de determinados conflictos sociales. La desigualdad económica o la violencia urbana, sirven para vertebrar discursos centrados 
en la distinción, la seguridad o la conservación de ciertos privilegios a las clases más favorecidas. De igual forma, el análisis de los mensajes vinculados al sector de la vivienda pueden expresar la evolución o tendencia en la priorización de determinados valores sociales en la sociedad contemporánea. Si antes hablábamos de la seguridad como una de las preocupaciones centrales en ámbitos urbanos, el particular uso del espacio y el tiempo, o desde una óptica etnográfica, la aparición de las personas en los mensajes, puede ser síntoma de la prevalencia de ciertos valores sobre otros.

Las zonas verdes o costeras, los espacios exteriores de las viviendas, el clima, las zonas de deporte o esparcimiento, la presencia de modelos o estereotipos, podrían conectar con valores sociales imperantes como el deseo de privacidad, el aislamiento, la tranquilidad. También entrarían en este análisis otras variables como la familia, la libertad, el deporte, la belleza física o el ocio. A nivel demográfico, el análisis cuantitativo de la publicidad inmobiliaria podría llegar inclusive a ofrecer datos sobre crecimiento de ciudades o expansión y tendencia de determinadas zonas residenciales, en base al volumen de mensajes que son difundidos en los diferentes medios.

\section{Discusión}

Una vez realizado el acercamiento hermenéutico sobre el objeto de estudio de la publicidad inmobiliaria, estamos en disposición de materializar una propuesta teórica que, a partir de referentes inmediatos, aporte una interpretación llamada a transformar y contribuir al conocimiento del fenómeno. A partir de la comprensión crítica y objetiva de los textos, rescatamos todo aquello que posibilite un conocimiento más amplio y profundo. Todo ello bajo el convencimiento de que la revisión que hemos llevado a cabo siempre es mejorable en términos cuantitativos y cualitativos, por estar restringida al estudio de las fuentes accesibles y por cuestiones de espacio y concreción teórica.

El marco teórico sobre el que podría cimentarse un acercamiento a la publicidad inmobiliaria hoy, podría integrar aspectos esenciales del sector inmobiliario como sector productivo en las sociedades industrializadas, su incidencia a escala macro y microeconómica, su relevancia y conexiones con otros sectores como el financiero, el bancario, las materias primas, la política de empleo, la incidencia de los poderes legislativos y ejecutivos y la estructura de los medios de comunicación en cada caso. Son relevantes de igual forma los aspectos psicológicos, sociológicos y culturales en conexión con el sector de la vivienda, las formas de consumo y apropiación de éstas como bienes de consumo en la vida material, hábitos, comportamientos, actitudes, tendencias, valores sociales.

El estudio del fenómeno desde la óptica antropológica también resulta pertinente para nosotros en cuanto a sus conexiones con el consumo. $\mathrm{Ha}$ blamos de los rituales de consumo en cuanto a la adquisición y uso de la vivienda, la transmisión de sentido y los mecanismos de vinculación en el círculo: sociedad-marcas-consumidores. La retórica, semiótica como herramientas de análisis de los discursos, pondrá en evidencia aquellas características y peculiaridades de los mensajes en relación a sus condiciones de producción, circulación y consumo de los discursos. Sistema publicitario, medios de comunicación, mediatización y sector inmobiliario en sus diversas formas de expresión.

Por último y a modo de pegamento que conecta y da sentido al corpus teórico, rescatamos la mediatización como concepto situado en la centralidad de la investigación en comunicación actual, a partir de las reflexiones sobre la influencia de los medios de comunicación social y la publicidad sobre los actos de consumo en el sector de la vivienda. En línea con el pensamiento de Hjarvard (2016), el concepto de mediatización como soporte teórico puede ofrecer un cuadro macro-sociológico para investigar cómo, de diferentes formas, los medios, la cultura y la sociedad interactúan. La teoría sugiere proposiciones generales sobre cómo esa interacción sucede.

Nuestra propuesta teórica además de ser una manera óptima de desentrañar los vínculos de sentido en el ámbito del consumo inmobiliario, abriría un extenso campo de estudio empírico para comprender los mecanismos que rigen diversos sectores de la vida material. En el caso que nos ocupa, estimamos que el análisis de la publicidad inmobiliaria 
es una aplicación excelente para comprobar la viabilidad de nuestra propuesta. El análisis de la publicidad como maquinaria de comunicación y expansión de los bienes en el mundo material (mediado por las marcas) es un revelador sociocultural privilegiado que trasciende los medios clásicos para acercarse a la cotidianidad de las personas.

La burbuja española durante el período 1997-2006 se nos muestra como un contexto idóneo para la realización de un estudio empírico fundamentado en el marco teórico que aquí presentamos. Un estudio pertinente para conocer cómo fuimos durante los años de la burbuja inmobiliaria y qué mecanismos discursivos generó la publicidad inmobiliaria para vender las viviendas. Los resultados del estudio fundamentado en el marco que aquí presentamos y articulado en base a un diseño metodológico construido ad hoc, podrían servir para su aplicación a otros ámbitos geográficos como es el caso del sector de la vivienda en Brasil.

\section{BIBLIOGRAFÍA}

AAKER, David \& MYERS, John. (1984), Management de la Publicidad. Barcelona, Hispano Europea.

ABADÍA, Leopoldo. (2009), La crisis ninja y otros misterios de la economía actual. Madrid, Espasa Calpe.

AGAMBEN, Giorgio. (2010), O que é o contemporâneo? E outros ensaios. Chapecó, Argos.

AL-HOMOUD, Majd; AL-OUN, Salem; SMADI, Ayat \& Al-Hindawi, Al-Mutasem. (2009), "Exploring sales advertising in the housing market in Jordan”. International Journal of Housing $M a$ rkets and Analysis, 2 (1): 39-56.

ALVES DIAS, Maria Cristina. (2008), Publicidade imobiliária e a construção de lugares simbólicos como extensáo de identidades. XIII Congreso de Ciencias da Comunicação na Regiao Sudeste. Sao Paulo. Disponible en http://www.intercom. org.br/papers/regionais/sudeste2008/resumos/ r9-0216-1.pdf, consultado en 19/10/2012.

. (2009), Publicidade imobiliária e suas construçôes retóricas. XXXII Congreso Brasileiro de Ciencias de Comunicação, Curitiba. Disponible en http://www.intercom.org.br/papers/nacio-
nais/2009/resumos/R4-1304-1.pdf, consultado en $19 / 10 / 2012$.

AMENDOLA, Giorgio. (2000), La ciudad postmoderna. Madrid, Celeste.

AUGÉ, Marc. (1989), Domaines et chateaux. París, La Librairie du XXe siècle/Seuil.

. (2008), Los no lugares, espacios del anonimato. Barcelona, Gedisa.

BARRERA, Carlos Roberto. (2011), "Publicidad formal de servicios inmobiliarios en Bogotá y latinoamérica. ¿Otro 'termómetro' del crecimiento urbano?". Estudios Demográficos y Urbanos, 26 (3): 709-733.

BAUDRILLARD, Jean. (2007), El sistema de los objetos. Madrid, Siglo XXI.

BENAVIDES, Juan. (2012), "La investigación en comunicación y publicidad: nuevos temas y problemas". Questiones Publicitarias, 1 (17): 71-93.

BRAUDEL, Ferdinand. (1970), La dinámica del capitalismo. México, DF, Fondo de Cultura Económica.

BOURDIEU, Piere. (2000), Las estructuras sociales de la economía. Barcelona, Anagrama.

BURRIEL DE ORUETA, Eugenio. (2008), "La década prodigiosa del urbanismo español (19972006)”. Scripta Nova, 12 (270). Disponible en http://www.ub.edu/geocrit/sn/sn-270/sn-27064.htm\#_edn6, consultado en 6/11/2011.

CAMPBELL, Colin. (2001), A ética romântica e o espírito do consumismo moderno. Rio de Janeiro, Rocco.

CAMPOS ECHEVERRÍA, José Luís. (2008), La burbuja inmobiliaria española. Barcelona, Marcial Pons.

CASAQUI, Vander. (2011), "Por uma teoria da publicização: transformaçōes no processo publicitário". Anais do XXXIV Congresso Brasileiro de Ciências da Comunicação, Intercom/Unicap, 1: 1-15.

CASTRO, Yolanda \& CALVO, Gloria. (1995), Estado del arte sobre la investigación de la familia en Colombia. Bogotá, Centro/Ministerio de Salud, ICBF.

CHECA GODOY, Antonio. (2007), Historia de la publicidad. A Coruña, Netbiblo.

CODELUPPI, Vanni. (2007), "El papel social de la publicidad”. Pensar la Publicidad, 1 (1): 149155. 
COLLINS, Damian \& KEARNS, Robin. (2008), "Uninterrupted views: real-estate advertising and changing perspectives on coastal property in New Zealand". Environment and Planning A, 40 (12): 2914-2932.

COLOMINA, Beatriz. (2010), Privacidad y publicidad: la arquitectura moderna como medio de comunicación de masas. Murcia, Cendeac.

CONTRERAS, Fernando. (2013), La cultura errabunda: arte, publicidad y posmodernidad. IV Encontro Nacional de Pesquisadores em Publicidade e Propaganda. São Paulo, USP. Disponible en http://www2.eca.usp.br/propesq/ downloads/ebook_IV_Propesq_pp.pdf, consultado en $26 / 10 / 2012$.

COULDRY, Nick. \& HEPP, Andreas. (2013), "Conceptualizing mediatization: contexts, traditions, arguments". Communication Theory, 23 (3): 191-102. Disponible en http://dx.doi. org/10.1111/ comt.12019, consultado en 21/02/2012.

DE CERTEAU, Michel. (2000), La invención de lo cotidiano. Vol. 1: Artes de hacer. México, DF, Universidad Iberoamericana, Departamento de Historia.

DOUGLAS, Mary \& ISHERWOOD, Baron. (1978), The world of goods: towards an anthropology of consumption. Nueva York, W.W. Norton Co.

EGUIZÁBAL, Raúl. (2007), Teoría de la publicidad. Madrid, Cátedra.

ESKJÆR, Mikkel. (2013), “The mediatization of ethical consumption”. MedieKultur, 54: 2646. Disponible en http://ojs.statsbiblioteket. $\mathrm{dk} /$ index.php/mediekultur/article/view/7274, consultado en 30/7/2014.

FAUSTO NETO, Antonio. (2010), "As Bordas da circulação...". Revista Alceu, 10 (20): 55-69.

GARCIA CANCLINI, Nestor. (1995), Consumidores y ciudadanos. México, Grijalbo.

GÓMEZ, P. \& RACCIATTI, C. (2013), “Tendencias en publicidad: una mirada desde Chile. El imaginario de la vivienda”, in C. Pérez y E. Trindade (orgs.), Por uma Publicidade Livre Sempre - IV Pró-Pesq PP. Encontro Nacional de Pesquisadores em Publicidade e Propaganda. Disponible en http://www.eca.usp.br/pro-
pesq/downloads/ebook_IV_Propesq_pp.pdf, consultado en 23/6/2014.

GONZÁLEZ MARTÍN, Juan Antonio. (1982). Fundamentos para la teoría del mensaje publicitario. Madrid, Forja.

GRAMLICH, Edward. (2008), "Auge y quiebras: el caso de las hipotecas subprime". Boletín del Cemla, 54 (1): 6.

GREIMAS, Algirdas J. (1984), "Semiótica figurativa e semiótica plastica”. Significaçao, 4: 1846. Disponible en http://dx.doi.org/10.11606/ issn.2316-7114.sig.1984.90477, consultado en $3 / 7 / 2012$.

HELLÍN ORTUÑO, Pedro Antonio. (2007), Publicidad y valores posmodernos. Madrid, Siranda.

HELLÍN ORTUÑO, Pedro Antonio; FERNÁNDEZ RINCÓN, Antonio Raúl (2007), “Los mecanismos discursivos de la publicidad inmobiliaria”, in El nuevo diálogo social: organizaciones, públicos y ciudadanos, Valencia, Campgrafia, pp. 739-750.

HÉLIO JUNQUEIRA, Antonio. (2010), “Construçôes retóricas na publicidade imobiliária brasileira contemporânea: encantamento e cinismo frente às aspirações do morar bem" I Encontro Luso-Brasileiro de Estudos do Consumo Tendências e Ideologias do Consumo no Mundo Contemporâneo, Rio de Janeiro, Septiembre 15-16-17.

HENRIQUE, Wendel. (2011), "Mercado imobiliário e mercatilização da natureza em salvador e regiāo metropolitana". Mercator Fortaleza, 10 (21): 63-80.

HERNÁNDEZ, Caridad. (1998), "Creatividad publicitaria y contexto social”, Zer, 4. Disponible en www.ehu.es/zer/caridad11.html, consultado en 3/7/2014.

HJARVARD, Stig. (2014), "Midiatização: conceituando a mudança social e cultural". Matrizes, 8 (1): 21-44. Disponible en http://dx.doi. org/10.11606/issn.1982-8160.v8i1p21-44, consultado en 19/8/2015.

IBÁÑEZ. JESÚS. (1994), Por una sociología de la vida cotidiana. Madrid, Siglo XXI.

IBELINGS, Hans. (1998), Supermodernismo: arquitectura en la era de la globalización. Barcelona, Gustavo Gili. 
JANSSON, Andre. (2002), "The mediatization of consumption: towards an analytical framework of image culture". Journal of Consumer Culture, 2 (2): 5-31. Disponible en http://dx.doi. org/10.1177/ 146954050200200101, consultado en $16 / 8 / 2015$.

JENCKS, Charles. (1996), El lenguaje de la arquitectura posmoderna. Barcelona, Gustavo Gili.

JUAN, Jorge. (seud.) (2000), Nada es gratis: cómo evitar la década perdida tras la década prodigiosa. Barcelona, Destino.

KOTLER, Philip et al. (coords.). (2012), Marketing 3.0. Madrid, Lid.

LAWSON, Gill. (2013), "A rhetorical study of in-flight real estate advertisements as a potential site of ethical transformation in Chinese cities". Cities, 31: 85-95.

LI, Songqing. (2012), "The use of English in China's real estate advertising". English Today, 28 (3).

LIVIER, Verónica \& HERNÁNDEZ, César-Abraham. (2010), "Imaginarios habitacionales de la vivienda de lujo frente a la globalización. El caso de la ciudad de Guadalajara". Ace, 5 (14): 33-44. Disponible en www-cpsv.upc. es/ace/Articles_n14/articles_pdf/ACE_14_ SA_12.pdf, consultado en 7/1/2015.

LLANO LINARES, Nicolás. (2016), "Olhando além do campo: o desenvolvimento da agenda de pesquisa da midiatização" [Entrevista com Stig Hjarvard]. Matrizes, 10 (1): 89-102.

MANARIN D'AGOSTINI, Luciano L. (2010), "A bolha imobiliaria no Brasil está formada". Economia \& Tecnologia, 6 (23): 41-53.

MARTÍN BARBERO, Jesús. (2003), De los medios a las mediaciones: comunicación, cultura y hegemonía. Barcelona, Anthropos.

MAZAJ, Jelena. (2012), "Advertising model of residential real estate object in Lithuania". Science - Future of Lithuania, 4 (3): 278-287.

MENDONÇA, Mário \& SACHSIDA, Adolfo. (2012), Existe bolha no mercado imobiliário brasileiro? Brasilia, Instituto de Pesquisa Econômica Aplicada.

MCCRACKEN, Grant. (2003), Culture and consumption. Indianapolis, Indiana University.

MEJÍA ESCALANTE, Mónica-Elizabeth. (2009), "Del discurso inmobiliario a la habitabilidad del espacio residencial". Bitácora Urbano Territorial, 14 (1): 45-58.

MILLER, Daniel. (2012), Comsumption and its consequences. Cambridge, Polity Press.

MOIX, Llacer. (2010), Arquitectura milagrosa. Barcelona, Anagrama.

GARCÍA MONTALVO, José. (2003), "La vivienda en España: desgravaciones, burbujas y otras historias". Perspectivas del Sistema Financiero, 78: 1-43.

PARANOS FERREIRA, Carlos Eduardo. (2012), Natureza e cidade: a conceitualização e o tratamento do residencial na publicidade imobiliária (análise contrastiva - décadas de 1970 e 2000). Campinas, tese de doutorado, Universidade Estadual de Campinas, Instituto de Artes.

PRYCE, Gwilym \& OATES, Sarah. (2008), "Rhetoric in the language of real estate marketing". Housing Studies, 23 (2): 319-348. Disponible en http://dx.doi. org/10.1080/02673030701875105 consultado en $4 / 7 / 214$.

RENNO, Raquel. (2003), "A cidade das marcas: marcas na cidade". Trabalho apresentado no XXVI Congresso Anual em Ciência da Comunicação, Belo Horizonte (MG).

RITZER, George. (2000), El encanto de un mundo desencantado: revolución en los medios de consumo. Madrid, Ariel.

RUSELL, J. Thomas \& LANE, W. Ronald. (2001), Kleppner publicidad. México, Pearson.

SAN NICOLÁS ROMERA, César. (2008), "Publicidad, persuasión y modalidades creativas. ¿Podemos hablar de una comunicación inteligente?", in Hellín Ortuño y Pedro Antonio (coords.), El discurso publicitario contemporáneo: su relación con lo social. Murcia, DM.

SCHILLER, Robert J. (2003), Exhuberancia irracional. Madrid, Turner.

SCHWARZ, M. (2012). “¿Cómo leer un paper de investigación científica?”. Disponible en http://max-schwarz. blogspot.com/2012/12/ como-leer-un-paper-de-investigacion.html, consultado en 15/9/2016.

SEMPRINI, Andrea. (2006), A marca pós-moderna: poder e fragilidade da marca na sociedade contemporânea. São Paulo, Estação das Letras. 
SERRANO- MARTINEZ, José María; GARCIA-MARIN, Ramón \& LAGAR-TIMON, David. (2016), "Housing, population and region in Spain: a currently saturated property market with marked regional differences". The Geographical Journal. Disponible en doi:10.1111/ geoj.12187, consultado en 15/9/2016.

SKLAIR, Leslie. (2010), "Iconic architecture and the culture-ideology of consumerism". Theory, Culture \& Society, 27 (5): 135-159. Disponible en http://dx.doi.org/10.1177/0263276410374634, consultado en 5/12/2015

STIGLITZ, Joseph E. (1990), "Symposium on Bubbles." Journal of Economic Perspectives, 4 (2): 13-18.

TADEI FERRAZ, Sonia Maria \& POSSIDÔNIO, Edson dos Reis. (2004), "Violência, medo e mercado: uma análise da publicidade imobiliária”. Impulso Piracicaba, 15 (37): 79-88.

TRIAS DE BES, Fernando. (2009), El hombre que vendió su casa por un tulipán. Barcelona, Temas de Hoy.

TRINDADE, Eneus e PEREZ, Clotilde. (2014). "Dimensões do consumo midiatizado". II Confibercom. Braga, Universidade do Minho. VERÓN, Eliseo. (2005), Fragmentos de um tecido. São Leopoldo, Editora Unisinos. . (2014), "Teoria da midiatização: uma perspectiva semioantropológica e algumas de suas consequências". Matrizes, 8 (1): 13-19. Disponible en http://dx.doi.org/10.11606/issn.19828160.v8i1p13-19, consultado en 12/9/2015.

WILLIAMS, Jerome; QUALLS, William \& GRIER, Sonya. (1995), "Racially exclusive real estate advertising: public policy implications for fair housing practices". Journal of Public Policy \& Marketing, 14 (2): 225-244.

WILLIAMSON, Judith. (1978), Decoding advertisements: ideology and meaning in advertising. London, Marion Boyars. 


\section{COMPREENDER A BOLHA IMOBILIÁRIA NA ESPANHA: UMA VISÃO MIDIATIZADA DA PUBLICIDADE}

\section{Antonio Raúl Fernández Rincón, Eneus Trindade e Pedro Antonio Hellín Ortuño}

Palavras-chave: Consumo; Publicidade; Mercado imobiliário; Bolha imobiliária

O mercado imobiliário tem alcançado, durante as últimas décadas, uma enorme transcendência em nível econômico, político e social em grande parte das economias desenvolvidas. Nosso objetivo se centra no estudo deste setor a partir do âmbito publicitário. Para isso, e como parte de um projeto maior, abordamos aqui a construção de um marco teórico a partir de uma revisão hermenêutica que resgata o conhecimento existente e necessário mais atualizado e que se compóe do conhecimento desde diferentes ramos das Ciências Sociais. Trata-se de uma proposta teórica de referência com um enfoque interdisciplinar que abarca aspectos econômicos, sociais, antropológicos, políticos, culturais e midiáticos. Mediante o estudo empírico posterior, nos servirá para desenhar os mecanismos discursivos da publicidade imobiliária na Espanha durante o recente boom da moradia, cujos resultados poderiam servir como referente em outros âmbitos geográficos que atravessem situaçôes socioeconômicas similares.

\section{COMPRENDER LA BURBUJA INMOBILIARIA EN ESPAÑA: UNA VISIÓN MEDIATIZADA DESDE LA PUBLICIDAD}

Antonio Raúl Fernández Rincón, Eneus Trindade y Pedro Antonio Hellín Ortuño

Palabras-clave: Boom de la vivienda; España; Publicidad; Consumo; Mediatización

El mercado inmobiliario ha tenido durante las últimas décadas una enorme trascendencia a nivel económico, político y social en gran parte de las economías desarrolladas. Nuestro objetivo se centra en el estudio de este sector desde el ámbito

\section{UNDERSTANDING THE SPANISH PROPERTY BUBLE: A MEDIATIC VISION OF ADVERTISEMENT}

\section{Antonio Raúl Fernández Rincón, Eneus Trindade e Pedro Antonio Hellín Ortuño}

Keywords: Consumption; Advertising; Real estate market; Property buble

Real estate market has reached during the last decades a huge transcendence in economic, political, and social levels in most of the developed economies. The objective of this paper is to study this sector having as its scope the advertisement. For this, and as part of a greater project, we will discuss the construction of a theoretical event based on a hermeneutic revision that recovers the existing and more updated necessary knowledge that is composed of the knowledge and the researches from different branches of the Social Sciences. It proposes to be a theoretical framework with an interdisciplinary approach that includes economic, social, anthropological, political, cultural, and mediatic aspects. Through the later empirical study, it will serve to delineate the discursive mechanisms of real estate advertisement in Spain during the recent peak of real estate property, whose results could serve as a reference in other geographic scopes that face similar socioeconomic situations.

de la publicidad. Para ello, y como parte de un proyecto mayor abordamos aquí la construcción de un marco teórico a partir de una revisión hermenéutica que rescata el conocimiento existente y necesario más actualizado y que se compone de los conocimientos e investigaciones desde diferentes ámbitos de las ciencias sociales. Se trata de una propuesta teórica de referencia con un enfoque interdisciplinar que recoge aspectos económicos, sociales, antropológicos, políticos, culturales y mediáticos. Mediante el estudio empírico posterior, nos servirá para dibujar los mecanismos
COMPRENDRE LA BULLE IMMOBILIËRE EN ESPAGNE : UNE APPROCHE MÉDIATIQUE DE LA PUBLICITÉ

\section{Antonio Raúl Fernández Rincón, Eneus Trindade e Pedro Antonio Hellín Ortuño}

Mots-clés: Consommation; Publicité; Marché du logement; Bulle immobilière

Le marché du logement a atteint, au cours des dernières décennies, une grande importance au niveau économique, politique et social dans une large partie des économies plus développées. Notre objectif se concentre sur l'étude de ce secteur à partir du point de vue publicitaire. Pour cela, et dans le cadre d'un projet plus vaste, nous abordons ici la construction d'une étape théorique à partir d'une révision herméneutique qui récupère les connaissances existantes et nécessaires, mises à jour composées de connaissance et de recherches dans différentes branches des sciences sociales. Il s'agit d'une proposition théorique avec une approche interdisciplinaire qui inclut les aspects économiques, sociaux, anthropologiques, politiques, culturels et médiatiques. Une étude empirique postérieure nous servira pour dessiner les mécanismes discursifs de la publicité immobilière en Espagne pendant le récent boom immobilier, dont les résultats pourraient servir en tant que référence dans d'autres sphères géographiques qui passent par des situations socio-économiques similaires.

discursivos de la publicidad inmobiliaria en España durante el reciente boom de la vivienda, cuyos resultados podrían servir como referente en otros ámbitos geográficos que atraviesen situaciones socioeconómicas similares. 